\title{
Effectiveness of the SpineCor brace based on the standardized criteria proposed by the S.R.S. for adolescent idiopathic scoliosis - up to date results
} AB Circo*, C Coillard and CH Rivard

Address: Research Center, Sainte-Justine Hospital, \& University of Montreal, 3175 ch. Côte Ste-Catherine, Montréal, Québec, H3T 1C5, Canada

Email: AB Circo* - alin_circo@yahoo.ca

* Corresponding author

from 6th International Conference on Conservative Management of Spinal Deformities Lyon, France. 21-23 May 2009

Published: I4 December 2009

Scoliosis 2009, 4(Suppl 2):O54 doi:I0.II86/I748-7|6I-4-S2-O54

This abstract is available from: http://www.scoliosisjournal.com/content/4/S2/O54

(c) 2009 Circo et al; licensee BioMed Central Ltd.

\section{Objective}

The objective of this study was to verify the effectiveness of the Dynamic SpineCor brace for adolescent idiopathic scoliosis and to confirm the stability of the results two years after the end of the treatment.

\section{Study design}

From 1993 to 2009, 840 patients were treated using the SpineCor brace. 413 patients fitted the inclusion criteria recommended by the SRS committee, and 159 patients were still actively being treated. Ultimately, 254 patients had a definitive outcome. The assessment of brace effectiveness included the following: percentage of patients who had a $5^{\circ}$ or less curve progression and the percentage of patients who had $6^{\circ}$ or more progression; percentage of patients who have been recommended for or have undergone surgery before skeletal maturity; percentage of patients with curves exceeding $45^{\circ}$ at maturity (end of treatment); 2-years follow-up beyond maturity to determine the percentage of patients who subsequently underwent surgery.

\section{Results}

Successful treatment (correction $>5^{\circ}$ or stabilization \pm $5^{\circ}$ ) was achieved in 165 patients of the 254 patients $(64.9 \%)$ from the time of the fitting of the SpineCor brace to the point in which it was discontinued. 46 immature patients $(18.1 \%)$ required surgical fusion while receiving treatment. Two patients out of $254(0.7 \%)$ had curves exceeding $45^{\circ}$ at maturity.

\section{Conclusion}

The SpineCor brace is effective for the treatment of adolescent idiopathic scoliosis. Positive outcomes are maintained after the weaning of the brace, as 99 patients out of 106 (93.3\%) stabilized or corrected their Cobb angle. Moreover, out of the $93.3 \%, 12.3 \%$ of the patients still maintained their Cobb angle correction 2 years after the end of the treatment. 